\title{
Jean Desmarets de Saint-Sorlin, Marie-Madeleine ou le triomphe de la grâce
}

\section{Chiara Rolla}

\section{(2) OpenEdition \\ 1 Journals}

\section{Edizione digitale}

URL: https://journals.openedition.org/studifrancesi/40588

DOI: 10.4000/studifrancesi.40588

ISSN: 2421-5856

\section{Editore}

Rosenberg \& Sellier

\section{Edizione cartacea}

Data di pubblicazione: 1 juillet 2004

Paginazione: 180

ISSN: 0039-2944

\section{Notizia bibliografica digitale}

Chiara Rolla, «Jean Desmarets de Saint-Sorlin, Marie-Madeleine ou le triomphe de la grâce», Studi

Francesi [Online], 142 (XLVIII | I) | 2004, online dal 30 novembre 2015, consultato il 09 septembre 2021. URL: http://journals.openedition.org/studifrancesi/40588 ; DOI: https://doi.org/10.4000/studifrancesi. 40588

Questo documento è stato generato automaticamente il 9 septembre 2021.

\section{(c)}

Studi Francesi è distribuita con Licenza Creative Commons Attribuzione - Non commerciale - Non opere derivate 4.0 Internazionale. 


\title{
Jean Desmarets de Saint-Sorlin, Marie-Madeleine ou le triomphe de la grâce
}

\author{
Chiara Rolla
}

\section{NOTIZIA}

JEAN DESMARETS DE SAINT-SORLIN, Marie-Madeleine ou le triomphe de la grâce, texte présenté, établi et annoté par GILLES BANDERIER, Grenoble, Millon, 2001, 221p.

1 Pubblicata nel 1669, la Marie-Madeleine di Desmarets è un punto di riferimento importante nella Querelle des Anciens et des Modernes e «titre d'excellence pour la France en matière d'écriture du merveilleux chrétien» (quarta di copertina). Nell'Introduzione Banderier ripercorre la vita dell'autore, ricostruendone la figura e collocando la Marie-Madeleine all'interno di una produzione vastissima e importantissima per comprendere la complessità di un'epoca così ricca e varia in tutti i suoi aspetti.

2 L'edizione ha rispettato il più possibile l'ortografia originale e ripropone le note infrapaginali previste dallo stesso Desmarets. Il volume contiene anche un glossario succinto dei termini desueti e una bibliografia critica selezionata di libri e articoli dedicati al tema e alla figura della Maddalena nel XVII secolo. 